\title{
Determination of Size Distribution of Guinier-Preston Zones in Al-Ag Alloys by Small-Angle X-ray Scattering Method
}

\author{
B. Bierska AND L. PAJAzK \\ Institute of Physics and Chemistry of Metals \\ University of Silesia, Bankowa 12, 40-007 Katowice, Poland
}

\begin{abstract}
Small-angle X-ray scattering method recognised to be very useful in the studies of structural problems of materials inhomogeneous in nanoscale. Studies by small-angle $\mathrm{X}$-ray scattering on the $\mathrm{Al}-\mathrm{Ag}$ alloys are presented. The size distributions of spherical Guinier-Preston zones were calculated using Vonk's and Glatter's methods. Small-angle X-ray scattering studies were performed on Al-5.0 at.\%Ag alloy containing spherical Guinier-Preston zones in the $\eta$-state. For this alloy one can assume that scattering particles are of spherical shape, have uniform electron density and scatter independently. Moreover, the size distributions were calculated for $\mathrm{Al}-1.6$ at.\% Ag alloy containing Guinier-Preston zones in $\varepsilon$-state (scattering particles with not uniform electron density). Both, Vonk's and Glatter's, methods gave similar size distributions. Profiles of size distributions for Guinier-Preston zones in $\varepsilon$-state are more complex in comparison to Guinier-Preston zones in $\eta$-state. It is connected with a complex structure of Guinier-Preston zones in $\varepsilon$-state. A modification of the structure model of Guinier-Preston zones in $\varepsilon$-state is proposed.
\end{abstract}

PACS numbers: $61.10 . \mathrm{Eq}, 81.40 . \mathrm{Cd}, 64.75 .+\mathrm{g}$

\section{Introduction}

The small-angle X-ray scattering (SAXS) method gives information on material structure when the electron density difference between some regions and surrounding medium is observed. The size of these regions lies in the range from 10 to $1000 \AA[1]$. 
SAXS method appeared to be very useful in the studies of different aspects of structure of alloys [2]. The earliest stages of coherent precipitation, it means, the formation of Guinier-Preston (GP) zones in supersaturated alloys was particularly investigated. $\mathrm{Al}-\mathrm{Ag}, \mathrm{Al}-\mathrm{Zn}, \mathrm{Al}-\mathrm{Cu}, \mathrm{Al}-\mathrm{Li}$ were most often applied as model alloys in these studies. The knowledge of the shape and size of GP zones and the concentration of soluble atoms inside and outside zones is of prime importance.

The profile of SAXS curve depends mainly on the shape, size, and concentration of the scattering regions. Interpretation of SAXS data is considerably simplified when the concentration of these regions is relatively small (generally less than $\sim 5$ vol. $\%$ ) and they are widely separated. In this case these regions are called "particles".

If the shape of particles is approximately the same (spherical, lamellar, rod-like) and known, the size distribution from SAXS data can be determined if the following conditions are fulfilled:

- particles have uniform electron density,

- non-spherical particles do not have preferential orientation with respect to the primary beam,

- probability of the particle position in the sample is the same for each point inside the sample,

- particles scatter independently,

- multiple scattering is negligible.

Vonk's [3] and Glatter's [4] methods were applied for the size determination of spherical GP zones in Al-Ag alloys. Both methods differ greatly in theoretical approach and enable the determination of size distribution without imposing any a priori functional shape.

\section{Characteristics of material}

$\mathrm{Al}-\mathrm{Ag}$ alloys are characterised by very small misfits of atom size thus the decomposition of these alloys starts by the formation of almost spherical GP zones. Since the work of Borelius and Larsson [5] and Baur and Gerold [6] it was accepted that depending on the temperature of ageing two different states of GP zones should be distinguished. Different structure models were proposed (Fig. 1). Below $\sim 170^{\circ} \mathrm{C}$ the zones are in $\eta$-state and are of uniform electron density (Fig. 1a). Above this temperature the zones are in $\varepsilon$-state which generally are not of uniform electron density (Fig. 1b-d). Kostorz with co-workers [8, 11-13] especially extensively studied different aspects of GP zones formation in Al-Ag alloys. They excluded model presented in Fig. $1 \mathrm{~b}$ and found that these zones are characterised by gradual change in composition and internal Ag distribution with an increase in ageing temperature. This change may be connected with the formation of Ag 


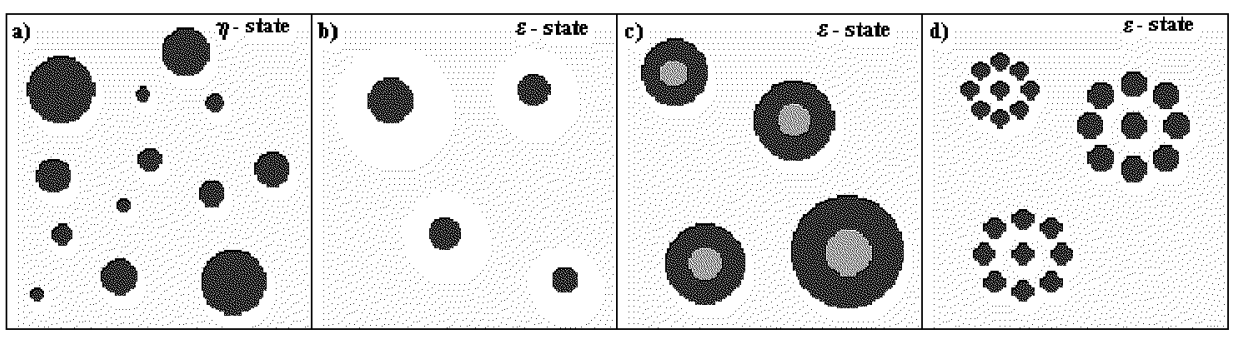

Fig. 1. The idealised structure models of GP zones in Al-Ag alloys (more dark regions correspond to greater concentration of Ag atoms): (a) two-phase model, $\eta$-state; (b) three-phase model, $\varepsilon$-state; (c) three-phase model, $\varepsilon$-state; (d) two-phase model, $\varepsilon$-state.

enriched outer shell (Fig. 1c) or Ag enriched regions inside GP zones (Fig. 1d). Generally, the models presented in Fig. 1c and Fig. 1d are similar.

\section{Experimental and discussion of results}

SAXS curves for thin, polycrystalline foil of $\mathrm{Al}-\mathrm{Ag}$ alloys were recorded with Kratky-type camera made by Jeol. Ni-filtered $\mathrm{Cu} K_{\alpha}$ radiation with a pulse height analyser was employed. The SAXS studies were performed starting from slit smeared intensities. The infinite beam length conditions were satisfied. Parasitic scattering on slits of collimator system was subtracted. Background connected with Laue monotonic scattering was also taken into account [14].

The size distributions of spherical GP zones for two samples of $\mathrm{Al}-5$ at.\% $\mathrm{Ag}$ alloy containing zones in the $\eta$-state are presented in Fig. 2. For these samples one can assume that the scattering particles have approximately a spherical shape, scatter independently and have uniform electron density. The values of $D \nu(2 R)$ are in a relative scale and $D \nu(2 R) d(2 R)$ is proportional to volume fraction of scattering zones with a size ranging from $2 R$ to $2 R+d(2 R)$. The profiles of the main maximum of size distributions calculated by Vonk's and Glatter's methods are almost identical. Negative values of size distributions have not a physical sense especially when the surface areas of negative and positive parts of size distribution oscillations are similar which is the case for the results presented in Fig. 2. Such oscillations appear when the size distributions are relatively narrow.

The values of mean diameter of spherical particles $2 R_{R \mathrm{~g}}$, which correspond to the determined radius of gyration $R_{\mathrm{g}}\left(2 R_{R \mathrm{~g}}=2.6 R_{\mathrm{g}}\right)$ are also marked in Fig. 2 . It is clearly seen that the values of the gyration radius overestimate the size of the scattering particles. This shows the necessity of determination of particle size distribution function. The knowledge of size distributions of GP zones may be very useful in the proper verification of the coarsening mechanism following nucleation stage of phase separation.

The size distributions for two samples of Al-1.6 at.\% Ag alloy containing GP zones in $\varepsilon$-state are presented in Fig. 3. Distribution of $\mathrm{Ag}$ atoms inside these zones 

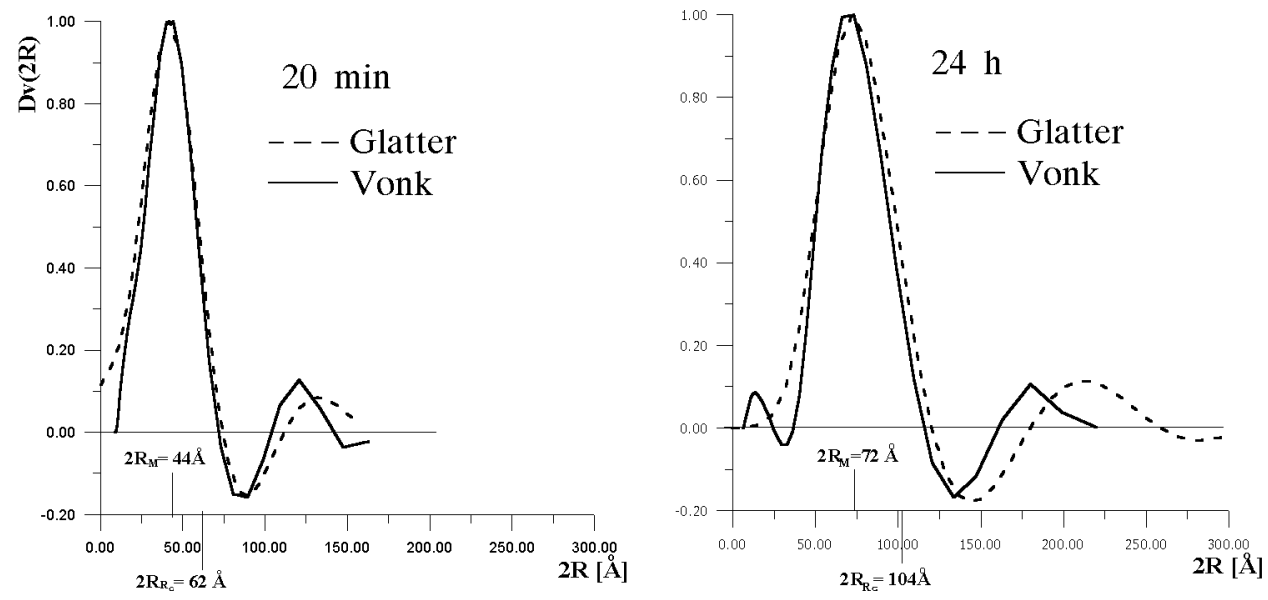

Fig. 2. Size distributions of GP zones in $\eta$-state (samples aged at $160^{\circ} \mathrm{C}$ for $20 \mathrm{~min}$ and $24 \mathrm{~h}$ ).
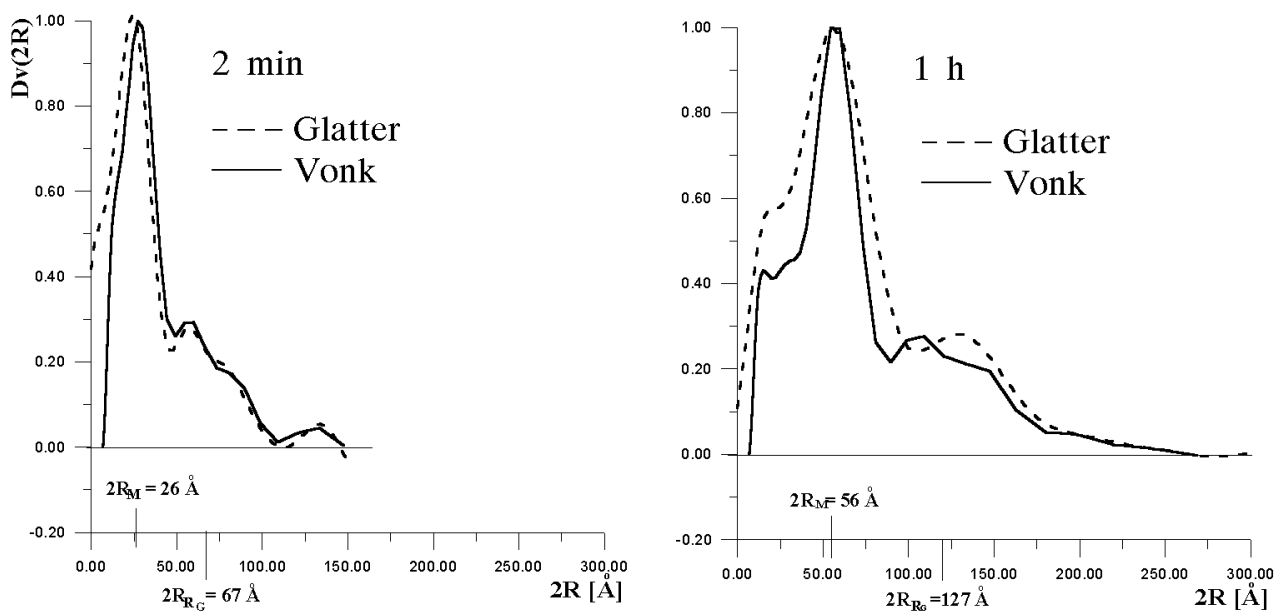

Fig. 3. Size distributions of GP zones in $\varepsilon$-state (samples aged at $200^{\circ} \mathrm{C}$ for $2 \mathrm{~min}$ and $1 \mathrm{~h})$.

is not uniform. The additional local maxima on the calculated size distributions of GP zones in $\varepsilon$-state are observed. It seems reasonable to ascribe these maxima to the more complex structure of the Guinier-Preston zones in $\varepsilon$-state. A significant difference between $2 R_{\mathrm{M}}$ location of main maximum of size distribution and $2 R_{R \mathrm{~g}}$ should be noted. Different distribution of Ag atoms inside GP zones in $\varepsilon$-state and $\eta$-state may be also evidenced by different profiles of Porod curves $\left(J(q) q^{3}\right.$ vs. $q$ for slit smeared SAXS data) without subtraction of any background (Fig. 4). The values $R_{\mathrm{g}}$ of radius of gyration are similar for both samples and equal to $42 \AA$ and 
$49 \AA$ for samples 1 (GP zones in $\eta$-state) and 2 (GP zones in $\varepsilon$-state), respectively. If in both samples the structure of scattering zones would be the same (spherical with uniform electron density) then, first of all, the profiles of both Porods curves should be similar and look like curve 1. Moreover the first local maximum for sample 2 would be more pronounced and shifted towards smaller $q$, in comparison with sample 1 . On the base of above consideration it seems that the distinction between $\eta$ - and $\varepsilon$-state of GP zones in $\mathrm{Al}-\mathrm{Ag}$ alloys should be maintained.

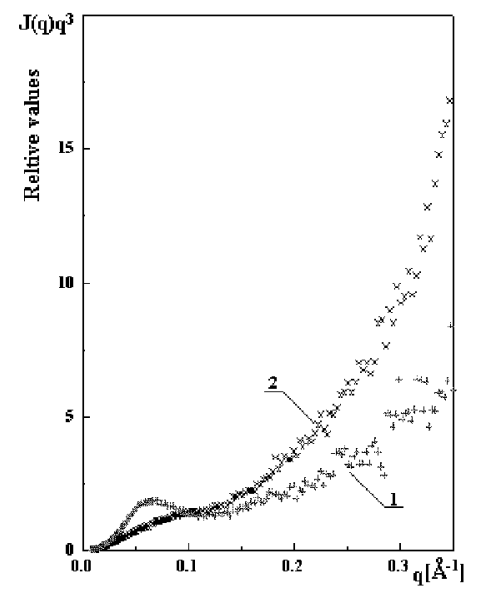

Fig. 4. Porod's plot for samples with GP zones in $\eta$-state (1) and $\varepsilon$-state (2).

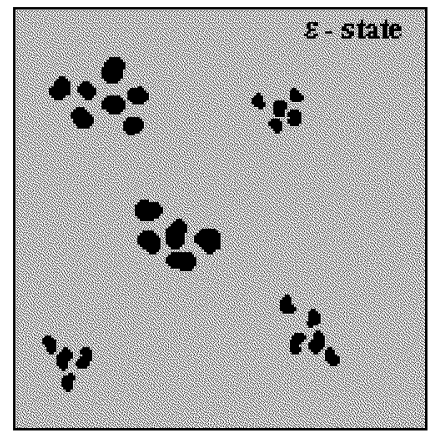

Fig. 5. Modification of two-phase structure model of GP zones in $\varepsilon$-state.

The modification of structure model of GP zones in $\varepsilon$-state presented in Fig. 1d is proposed in Fig. 5. It must be emphasised that the proposed structure model is not in contradiction with the SAXS results of Kostorz et al. [8, 11-13] (Ag enriching of outer shell is evident) and with the results of large-angle diffuse $\mathrm{X}$-ray scattering of Kostorz et al. [15]. It also takes into account the conclusion 
of Bischof et al. [16] from the studies of positron annihilation that GP zones in $\varepsilon$-state cannot be described by any of the multi-phase models.

\section{Conclusions}

From the presented results the following conclusion can be drawn:

- profile of SAXS intensity is very sensitive on the distribution of electron density inside scattering particles,

- reasonable size distribution can be calculated from SAXS data when the system of scattering particles satisfies the desired conditions,

- both Vonk's and Glatter's methods give similar particle size distributions.

The modified structure model of Guinier-Preston zones in $\varepsilon$-state for $\mathrm{Al}-\mathrm{Ag}$ alloys was proposed.

\section{References}

[1] A. Guinier, G. Fournet, Small-Angle X-ray Scattering, John Wiley and Sons, New York 1955.

[2] G. Kostorz, in: Physical Metallurgy, Eds. R.W. Cahn, P. Haasen, North Holland, Amsterdam 1991, p. 1116.

[3] C.G. Vonk, J. Appl. Crystallogr. 9, 433 (1976).

[4] O. Glatter, J. Appl. Crystallogr. 13, 7 (1980).

[5] G. Borelius, L.E. Larsson, Arkiv. Physik 11, 137 (1956).

[6] R. Baur, V. Gerold, Acta Met. 10, 637 (1962).

[7] A. Naudon, J. Caisso, J. Appl. Crystallogr. 7, 25 (1974).

[8] Ph. A. Dubey, B. Schönfeld, G. Kostorz, Acta Metall. Mater. 39, 1161 (1991).

[9] L. Pająk, in: Proc. X Conf. on Applied Crystallography, September 1980, Kozubnik, Eds. Z. Bojarski, T. Bold, Institute of Ferrous Metallurgy in Gliwice, Gliwice 1980, p. 64 .

[10] L. Pająk, Arch. nauki o mater. 61, 3 (1982) (in Polish).

[11] A. Malik, B. Schönfeld, G. Kostorz, J.S. Pedersen, Acta Mater. 44, 4845 (1996).

[12] A. Malik, B. Schönfeld, G. Kostorz, W. Bührer, J.S. Pedersen, Z. Metallkd. 88, 625 (1997).

[13] G. Kostorz, in: Proc. XVIII Conf. Applied Crystallography, September 2000, Wista (Poland), Eds. H. Morawiec, D. Stróż, World Scientific, Singapore 2001, p. 65.

[14] B.E. Warren, in: X-ray Diffraction, Addison-Wesley Publ., Reading 1969, p. 229.

[15] B. Schönfeld, A. Göcman, G. Kostorz, J. Phys. I (France) 2, 1075 (1992).

[16] G. Bischof, V. Gröger, G. Krexner, R.M. Nieminen, J. Phys., Condens. Matter 8, 7523 (1996). 